Check for updates

Cite this: J. Mater. Chem. C, 2019, 7, 2577

Received 11th December 2018, Accepted 18th January 2019

DOI: $10.1039 / c 8 t c 06254 d$

rsc.li/materials-c

\section{Luminescence tuning with excellent colour homogeneity and steadiness using fluorescent molecular liquids $\dagger$}

\author{
Fengniu Lu, (D) ${ }^{\text {a }}$ Keita Hagiwara, ${ }^{\text {b }}$ Michito Yoshizawa, (D) ${ }^{\mathrm{b}}$ Kazuhiko Nagura, (D) \\ Shinsuke Ishihara (D) and Takashi Nakanishi (D)*a
}

\begin{abstract}
Solvent-free multicolour-emitting soft materials are promising candidates for burgeoning flexible lightemitting devices. Although significant effort has been devoted to the colour tunability of luminophores, the quality of the colour has remained inconspicuous. In the present study, we achieved a homogeneous and steady regulated luminescence colour through the chemical modification of fluorescent molecular liquids. An alkylated 2,6-dibromo-9,10-diphenylanthracene liquid was used as a case study, the fluorescence of which was tuned by either extending the length of the $\pi$-conjugation or incorporating an intramolecular charge transfer transition. The resulting liquids emitted different colours spanning from deep blue to green. Each colour exhibits an advantageous uniformity and steadiness over those of conventional colour-tuning systems, such as the blending of a luminescent liquid with other emissive solid dopants, demonstrating significant promise for the long-term consistency of the end-use luminescent performance.
\end{abstract}

\section{Introduction}

The past few years have witnessed a rapid expansion of flexible, stretchable, and bendable light-emitting devices, such as curved organic light-emitting diode displays and pocketable e-ink newspapers. ${ }^{1}$ The development of such highly portable electronics is in urgent need of advanced soft materials that not only show multi-colour emissions, thereby achieving full-colour displays, but also exhibit significant colour accuracy, producing a superb image quality and highly stable optoelectronic properties allowing resistance to morphology changes, mechanical forces, and environmental fluctuations. Organic luminophores with intense emission in a solvent-free film $^{2}$ or a liquid crystalline ${ }^{3}$ state have thus come under the spotlight owing to their non-volatile nature, facile functionality, and wide emission tunability. To date, there are several ways to tune their emission colours: chemically modifying the emitting unit, ${ }^{4}$ controlling the molecular packing styles, ${ }^{5}$ co-assembling with suitable luminophores, ${ }^{6}$ and blending with other emissive materials. ${ }^{7}$

\footnotetext{
${ }^{a}$ International Center for Materials Nanoarchitectonics (WPI-MANA), National Institute for Materials Science (NIMS), 1-1 Namiki, Tsukuba 305-0044, Japan. E-mail: nakanishi.takashi@nims.go.jp

${ }^{b}$ Laboratory for Chemistry and Life Science, Institute of Innovative Research, Tokyo Institute of Technology, 4259 Nagatsuta, Midori-ku, Yokohama 226-8503, Japan $\dagger$ Electronic supplementary information (ESI) available: Experimental section, NMR, MALDI-TOF MS, additional figures, tables and movies as indicated in the main text. See DOI: 10.1039/c8tc06254d
}

However, most of these methods produce emission colours that are highly sensitive to the orientation and assembled structures of molecules. ${ }^{8}$ A subtle change in the substrate, ${ }^{9}$ an alteration of the processing method, ${ }^{10}$ or exposure to various external stimuli ${ }^{11}$ can abruptly alter the photophysical properties. Even for an amorphous solid film, the random aggregation of molecules results in a loss of colour evenness.

To achieve consistent and uniform optical properties, we and others have developed liquid luminophores ${ }^{12}$ through an alkyl- $\pi$ engineering strategy, ${ }^{13}$ i.e., wrapping $\pi$-conjugated dyes with bulky, flexible, and low-melting branched alkyl chains. A significant suppression of inter-chromophore interactions not only overcomes the aggregation-caused quenching effect ${ }^{14}$ in a condensed solvent-free state, but also prevents the emitting units from packing into a long-range order. As a result, these alkyl- $\pi$ liquids exhibit intense and homogeneous emissions with improved photostability. ${ }^{12 c}$ In addition, their fluidic nature facilitates excellent processing for fabrication into flexible/ bendable light-emitting devices. ${ }^{15}$ Despite the rapid development of luminescent liquids, the tuning of their emission colour remains in the preliminary stage. A widely accepted methodology is to blend a liquid with commercially available solid luminophores. ${ }^{12 b, c, 16}$ Although such a method exhibits good colour tunability, an evaluation of the consistency and homogeneity of the resulting colour has been overlooked. As a physical blending system, it is challenging to disperse solid dopants uniformly into a liquid matrix. Inhomogeneous mixing 

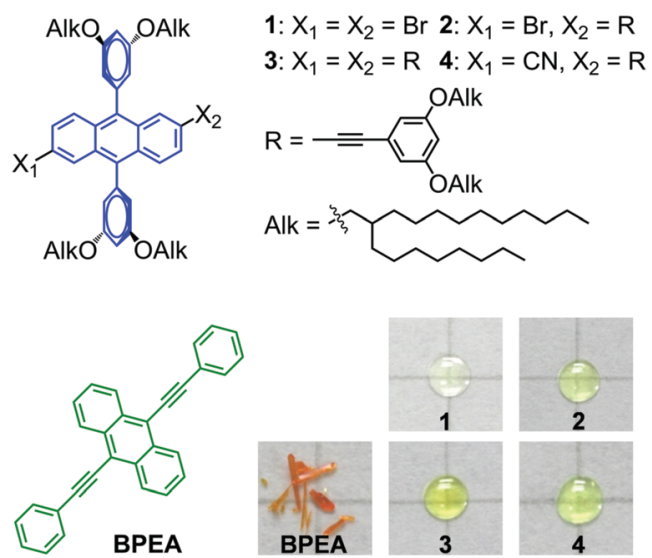

Fig. 1 Chemical structures and photographs of liquids 1-4 and the solid dopant BPEA. The photographs were taken under daylight conditions at ambient temperature, with a liquid drop of $\mathbf{1 - 4}$ or solid BPEA placed on a glass plate located on top of white-black squared paper.

undermines the colour uniformity and reproducibility, whereas phase segregation changes the optical properties. Therefore, it is of significant importance to explore a strategy that can regulate the fluorescence of liquids while maintaining the stability and uniformity of the emitted colour in a predictable manner.

As a luminescence tuning method, chemical modification gives rise to a new compound in a single phase, which can avoid problems in the mixing phases. Therefore, we have attempted to adapt the method to tune the emission colour of fluorescent molecular liquids. As a case study, a previously reported blue-emitting liquid $1\left(\lambda_{\mathrm{em}}^{\max }=444 \mathrm{~nm}\right)^{17}$ (Fig. 1) is utilized to show the feasibility and advantage of chemical modification in tuning the emission of molecular liquids. When adding a solid dopant 9,10-bis(phenylethynyl)anthracene (BPEA) (Fig. 1) into liquid 1, the emission turned to a greenish colour. However, fluorescence microscopy images showed clear aggregates of BPEA and an inhomogeneous colour distribution in 1-BPEA composites. In contrast, the chemical modification of $\mathbf{1}$, by either extending the length of the $\pi$-conjugation ( 2 and 3 ) or incorporating an intramolecular charge transfer (ICT) transition (2 and 4) through a functionalization of the 2- and 6-positions of the anthracene unit (Fig. 1), creates liquids with regulated emission colours from deep blue to a greenish blue. Each colour shows ideal homogeneity.

\section{Results and discussion}

\section{Synthesis of DPA derivatives}

Liquid 1 was synthesized according to a previously reported method. ${ }^{17}$ The Sonogashira coupling reaction from 1 with 1-ethynyl-3,5-bis(2-octyldodecyloxy)benzene produced compounds 2 and 3 . The subsequent cyanation of $\mathbf{2}$ yielded $\mathbf{4}$. All compounds were unambiguously characterized using ${ }^{1} \mathrm{H}$ nuclear magnetic resonance $\left({ }^{1} \mathrm{H} \mathrm{NMR}\right),{ }^{13} \mathrm{C} \mathrm{NMR}$, and matrix-assisted laser desorption ionization-time-of-flight mass spectrometry (MALDI-TOF MS). Compounds 1-4 were all obtained as viscous transparent fluids at room temperature (Fig. 1). The ${ }^{1} \mathrm{H}$ and ${ }^{13} \mathrm{C}$ NMR spectra confirm the absence of residual solvents in all samples (see the details in $\mathrm{ESI} \dagger$ ).

\section{Inhomogeneous fluorescence colour of liquid-solid composites}

To enrich the emission colours, liquid 1 was blended with a solid dye BPEA following the reported procedure. ${ }^{12 b, c, 16}$ BPEA was selected because its absorption band in a dilute solution overlaps well with the emission band of 1 (Fig. S1, ESI $\dagger$ ). Thus, an efficient Förster resonance energy transfer (FRET) ${ }^{18}$ will occur from 1 to BPEA if BPEA are molecularly dispersed in liquid 1, which can change the fluorescence colour from blue to green. Upon blending BPEA into 1, new absorption (400-480 nm) and emission (455-600 nm) bands attributable to BPEA appeared (Fig. 2a). The emission bands corresponding to 1 (400-455 nm) gradually decreased when increasing the ratio of BPEA from 0.1 (I) to 0.5 (II) $\mathrm{mol} \%$, with the relative fluorescence intensity ratios of $\mathbf{1}$ (at $444 \mathrm{~nm}$ ) to BPEA (at $475 \mathrm{~nm}$ ) being 0.33 in I to 0.08 in II, which is an indication that a FRET occurred. When plotting the $(x, y)$ coordinates of the fluorescence on a Commission Internationale de l'Eclairage (CIE) 1931 chromaticity diagram, the colour changes from deep blue (1) to light blue (I) to green (II) (Fig. 2b). To further modulate the colour toward the green region, BPEA is increased to 1.0 (III) and 5.0 (IV) mol\%. However, instead of further quenching, the emission from $1(400-455 \mathrm{~nm})$ is gradually recovered (Fig. 2a), with the relative fluorescence intensity of 1 (at $444 \mathrm{~nm}$ ) to BPEA (at $475 \mathrm{~nm}$ ) increasing to 0.17 in III and 0.33 in IV. In addition, the emission colour changes back to light blue (IV) (Fig. 2b), which is probably caused by the aggregation of BPEA in $\mathbf{1}$ at high concentrations, in other words, poor solubility of BPEA in 1.

Fluorescence microscopy images were recorded to evaluate the dispersion state of BPEA in liquid 1. Before blending with BPEA, liquid 1 exhibited a uniform deep-blue emission (Fig. 2c). After doping, Fig. 2c shows the dispersion of BPEA as micrometre-sized dots (denoted by arrows) shining brightly in the blue-emitting liquid at $0.1 \mathrm{~mol} \%$ (I). Upon increasing the ratio to $0.5 \mathrm{~mol} \%$ (II), aggregates of several tens of micrometres in length can be observed. At $1.0 \mathrm{~mol} \%$ (III), BPEA forms needle-like structures with lengths exceeding $50 \mu \mathrm{m}$, which are lengthened to hundreds of micrometres and aggregated into clusters at $5.0 \mathrm{~mol} \%$ (IV). The aggregates show a yellow emission, which is easily discriminated from the blue emission of the liquid matrix. Therefore, inhomogeneous emitting domains coexist in the composites. As shown in Fig. 2d, nonuniform emission colours are visible to the naked eye in composites with 1.0 (III) and 5.0 (IV) mol\% of BPEA. Furthermore, the aggregates can move randomly with the flow of liquids (Movie S1, ESI $\dagger$ ), suggesting non-steady local optical properties.

Severe aggregation of BPEA implies a strong tendency of a phase segregation in the composites, which is reflected in the thermal behaviours. As shown in Fig. 2e, 1 exhibits only $T_{\mathrm{g}}$ $\left(<-50{ }^{\circ} \mathrm{C}\right)$ in the differential scanning calorimetry (DSC) heating curve from -70 to $300{ }^{\circ} \mathrm{C}$. BPEA shows an endothermic $T_{\mathrm{m}}$ at $257{ }^{\circ} \mathrm{C}$, followed by an exothermic peak at $267{ }^{\circ} \mathrm{C}$ (decomposition at $485{ }^{\circ} \mathrm{C}$; Fig. S2, ESI $\dagger$ ), which can be assigned 

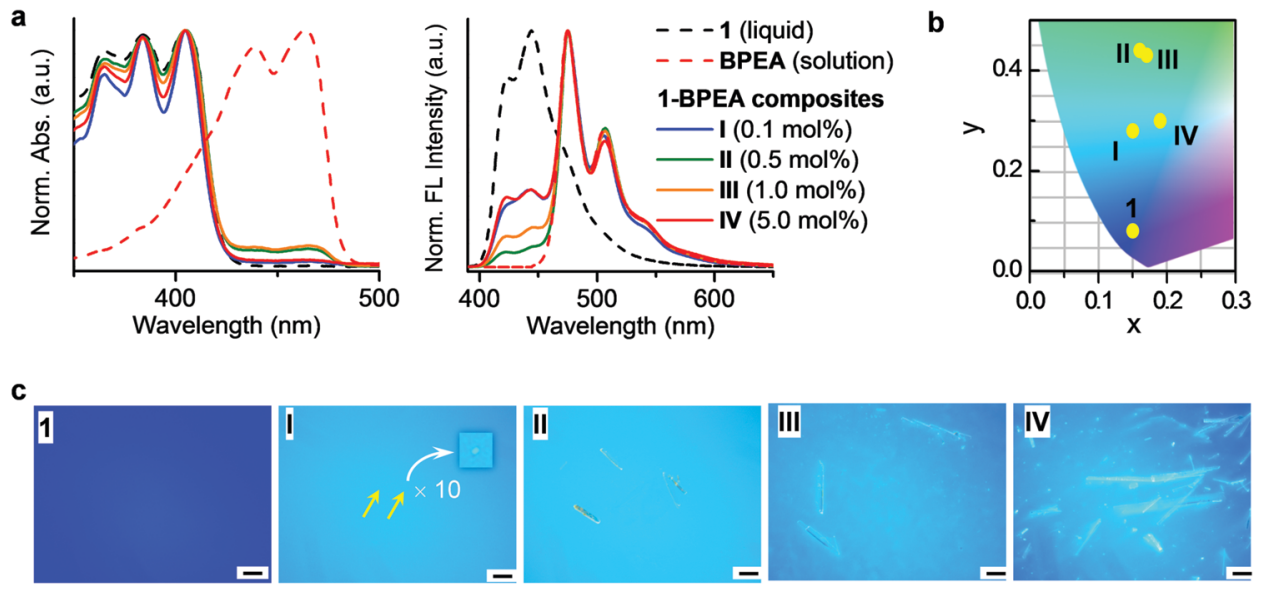

d

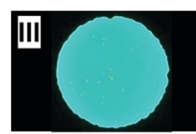

e

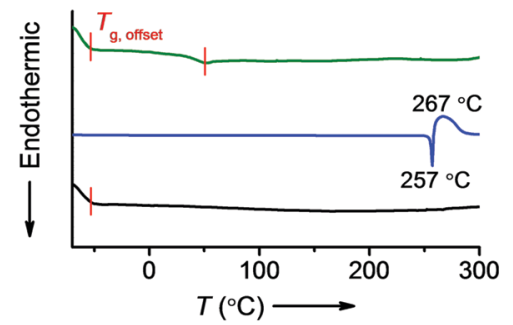

$\mathbf{f}$

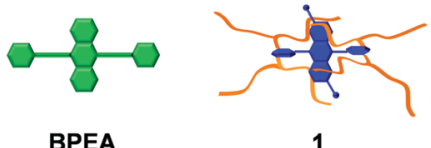

1

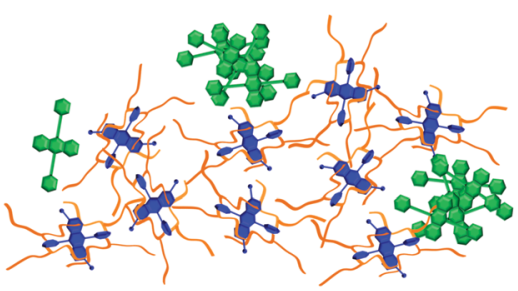

Fig. 2 (a) Normalized UV-vis absorption (left) and fluorescence (right) spectra of liquid $\mathbf{1}$ (blue), BPEA solution $\left(\mathrm{CH}_{2} \mathrm{Cl}_{2}, 10^{-6} \mathrm{M}\right)($ red), and solvent-free 1-BPEA composites with 0.1 (I, cyan), 0.5 (II, green), 1.0 (III, yellow), and 5.0 (IV, orange) mol\% of BPEA at $20^{\circ} \mathrm{C}$. (b) A section of a CIE 1931 chromaticity diagram for liquid 1 and composites I-IV. (c) Fluorescence micrographs of 1 and composites I-IV at $20{ }^{\circ} \mathrm{C}$. $\lambda_{\text {ex }}, 340-380 \mathrm{~nm}$. Scale bar, $50 \mu \mathrm{m}$. (d) Photographs of a drop of composites III (left) and IV (right) sandwiched between two glass plates under irradiation of a UV lamp ( $365 \mathrm{~nm}$ ) at $20{ }^{\circ} \mathrm{C}$. The diameter of the sample region is at the centimetre scale. (e) DSC thermograms of $\mathbf{1}$ (black line), BPEA (blue line), and composite IV (green line) during the first heating scan at $10{ }^{\circ} \mathrm{C} \mathrm{min}^{-1}$ under a nitrogen flow. (f) Schematic illustration of the phase segregation between liquid $\mathbf{1}$ and BPEA.

to the thermal crosslinking of the phenylethynyl moieties ${ }^{19}$ (Fig. S3 and Movie S2, ESI $\dagger$ ). For the composite IV, the glass-toliquid transition of $\mathbf{1}$ occurred, together with a new phase transition appearing at $52{ }^{\circ} \mathrm{C}$, which indicates the formation of a new species. We attributed this to the glass-to-liquid transition of the 1-BPEA solution in which a very low amount of BPEA was dissolved in 1. Our hypothesis was supported through variable-temperature optical microscopic observations. At below $52{ }^{\circ} \mathrm{C}$, the sample flowed extremely slowly, with a negligible change in the sample position (Fig. S4a, ESI $\dagger$ ). As soon as the temperature was elevated to $52{ }^{\circ} \mathrm{C}$, the flow of the sample was accelerated, during which the liquid spread quickly away from the solid aggregates (Fig. S4b and Movie S1, ESI $\dagger$ ). After cooling, the spreading liquid showed a blue emission in the outer region and greenish fluorescence in the inner area, which are ascribed to liquid $\mathbf{1}$ and the 1-BPEA solution, respectively (Fig. S4c(ii), ESI†). These observations indicate that the 1-BPEA composite contains three species: liquid 1, a 1-BPEA solution, and undissolved BPEA aggregates. Indeed, the composite underwent very slow phase segregation even at room temperature (Fig. S5, ESI $\dagger$ ). Therefore, the phase segregation affects both the microscopic local properties and the bulk characteristics in an unpredictable manner.

To further confirm the phase segregation between molecular liquids and $\pi$-conjugated solid dopants, we blended 1 with a frequently used solid additive, namely, yellowish emitting rubrene, ${ }^{12 b, 20}$ which may not form a severe aggregation owing to its steric molecular structure (Fig. S6a, ESI $\dagger$ ). However, bright shining dots were still observable in the 1-rubrene composites under fluorescence microscopy (Fig. S6b, ESI $\dagger$ ). In addition, severe phase segregation was observed after heating up to $200{ }^{\circ} \mathrm{C}$ (Fig. S6c, ESI $\dagger$ ), which is in sharp contrast to the consistent emission colour of 1 upon heating (Fig. S6d, ESI $\dagger$ ).

The phase segregation between $\mathbf{1}$ and BPEA (or rubrene) can be understood based on the 'like dissolves like' rule. ${ }^{21}$ According to our previous study on alkylated-fullerene liquids, ${ }^{22}$ the alkyl chains and $\pi$-moieties have different degrees of solvophobicity. Therefore, the alkyl chains and anthracene moieties in $\mathbf{1}$ are mutually immiscible, with a higher affinity of anthracene for a $\pi$-conjugated dye. Unfortunately, the enveloping alkyl chains hinder the anthracene from approaching and solvating the dye (Fig. 2f). Thus, the solid additives are driven to aggregate. 
Because most optoelectronically active organic materials are of $\pi$-conjugated skeletons, their aggregation in side-chainprotected molecular liquids is substantially ineluctable.

\section{Homogeneous fluorescence colour tuned through chemical modification}

To address this issue, an alternative strategy allowing the homogeneous tuning of the optoelectronic properties of molecular liquids is desired. We herein attempt to apply another conventional fluorescence tuning method, namely, chemical modification, to modulate the emission colour of alkyl- $\pi$ liquids, aiming to improve the quality of the resulting emission colour. In contrast to its non-brominated parent liquid, 9,10bis(3,5-di-2-octyldodecyloxy)phenylanthracene $\left(\lambda_{\mathrm{ex}}^{\max }=432 \mathrm{~nm}\right),{ }^{17}$ 1 exhibited a $12 \mathrm{~nm}$ bathochromic shift in the emission band, probably owing to a slight extension of the $\pi$-conjugation through bromination (see the decreased energy gap between the highest occupied molecular orbital (HOMO) and the lowest unoccupied molecular orbital (LUMO) in Fig. S7, ESI $\dagger$ ). We thus further extended the $\pi$-conjugation by attaching phenylethynyl groups to the anthracene core of $\mathbf{1}$, attempting to tune the fluorescence toward longer wavelengths. To maintain the kinetic stability of the liquid phase, the phenylethynyl substituent was modified with branched 2-octyldodecyloxy chains at the 3,5-positions of the phenyl unit. As shown in Fig. 1, a series of novel liquids, 2-4, was obtained in this manner (see the synthetic details in the ESI $\dagger$ ); all liquids exhibited variable fluorescence colours (Fig. 3a) and a high kinetic stability, which remained in a liquid state upon aging at ambient temperature for over 1 year (see also Fig. S8, ESI $\dagger$ ). In the DSC heating traces, only an endothermic glass-to-isotropic transition appeared at below $-50{ }^{\circ} \mathrm{C}$ for each compound (Fig. S8a and Table S1, ESI $\dagger$ ), suggesting a liquid state of 2-4 at room temperature. The amorphous liquid feature was further approved through an absence of texture in the polarized optical microscopy (POM) images at room temperature (Fig. S9, ESI $\dagger$ ).

All compounds in the solution showed three well-resolved absorption peaks (Fig. 3c). The longest absorption maxima are at $404 \mathrm{~nm}$ for $1,415 \mathrm{~nm}$ for 2 , and $430 \mathrm{~nm}$ for 3 , revealing a clear bathochromic shift from $\mathbf{1} \rightarrow \mathbf{3}$. This spectral shift can be attributed to the increasing number of phenylethynyl groups in $\mathbf{1} \rightarrow \mathbf{3}$, which extends the $\pi$-conjugation of the emitting unit. In agreement with this explanation, density functional theory (DFT) calculations revealed a decrease in the HOMO-LUMO energy gap upon increasing the conjugation length of the anthracene core (Fig. S7 and Table S1, ESI $\dagger$ ). The emission spectra of $\mathbf{1} \rightarrow \mathbf{3}$ in the solution also undergo bathochromic shifts (Fig. 3c), consistent with the trends in their absorption spectra.

Compound 4 in the solution exhibited bathochromic shifts in the UV-vis absorption and emission spectra as compared to 2 , despite both possessing a single phenylethynyl unit. The difference in electronic absorption should arise from the larger electron-withdrawing ability of the cyano group (in 4) than that of the bromine (in 2), namely, a larger ICT effect in 4 . As confirmed through DFT calculations, the energy of the LUMO orbital is decreased more by the cyano group than by
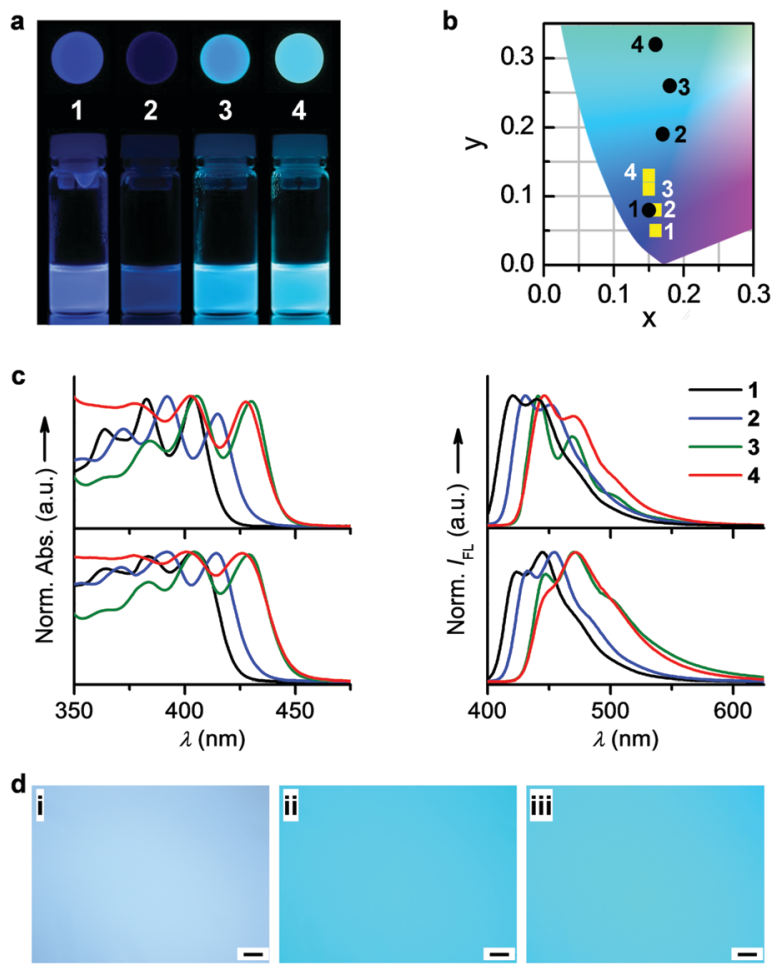

Fig. 3 (a) Photographs of 1-4 in a solvent-free liquid state (sandwiched between two glass plates) (upper) and in a $\mathrm{CH}_{2} \mathrm{Cl}_{2}$ solution $\left(10^{-4} \mathrm{M}\right.$ ) (lower) under irradiation of a UV lamp $(365 \mathrm{~nm})$. (b) A section of CIE 1931 chromaticity diagram for 1-4 in $\mathrm{CH}_{2} \mathrm{Cl}_{2}$ solution (yellow squares) and solvent-free liquid state (black circles). (c) Normalized UV-vis absorption (left) and fluorescence (right) spectra of $\mathbf{1}$ (black), $\mathbf{2}$ (blue), $\mathbf{3}$ (green), and $\mathbf{4}$ (red) in $\mathrm{CH}_{2} \mathrm{Cl}_{2}$ (UV-vis, $10^{-5} \mathrm{M}$; fluorescence, $10^{-6} \mathrm{M}$ ) (upper) and solventfree liquid state (lower). (d) Fluorescence micrographs of liquids 2 (i), 3 (ii), and 4 (iii) at $20^{\circ} \mathrm{C}$. Scale bar, $50 \mu \mathrm{m}$. $\lambda_{\text {ex }}: 340-380 \mathrm{~nm}$.

bromine, leading to a smaller HOMO-LUMO energy gap in 4 than in 2 (Fig. S7 and Table S1, ESI $\dagger$ ). The ICT natures of 2 and 4 were further confirmed through the bathochromic shifts of their optical spectra upon increasing the polarity of the solvents (Fig. S10 and Tables S2, S3, ESI $\dagger$ ). The emission maxima exhibited shifts of $8 \mathrm{~nm}$ for 2 and $14 \mathrm{~nm}$ for 4 upon changing the solvent from hexane to benzonitrile. According to Fig. 3c, the emission spectrum of 3 nearly overlaps with that of 4 . Therefore, both the extension of the $\pi$-conjugation and the introduction of electron-withdrawing groups can effectively tune the emission colour of pristine $\mathbf{1}$ in the solution.

The molecular optical features in a dilute solution are well retained in a solvent-free state. Compared with the corresponding solutions, the maximum absorption peaks for liquids 1-4 remain nearly constant (Fig. S11, ESI $\dagger$ ). Each compound exhibits a sharp and vibronic emission band with a maximum and shoulder peak in both the solution and liquid state. The relative emission intensities of the maximum and shoulder peaks of 1-4 differ between the solution and liquid because of the different media surrounding the chromophores, i.e., $\mathrm{CH}_{2} \mathrm{Cl}_{2}$ in the solution and chromophores in the liquid. Accordingly, the $\Phi_{\mathrm{FL}}$ (Table S1, ESI $\dagger$ ) and lifetime decays (Fig. S12 and Tables S4, S5, ESI $\dagger$ ) of 1-4 are altered from the solution to the liquid state. 


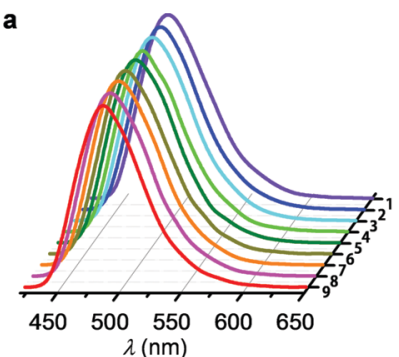

b

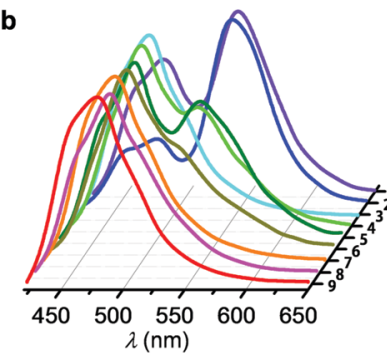

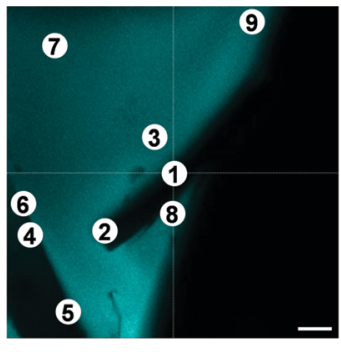
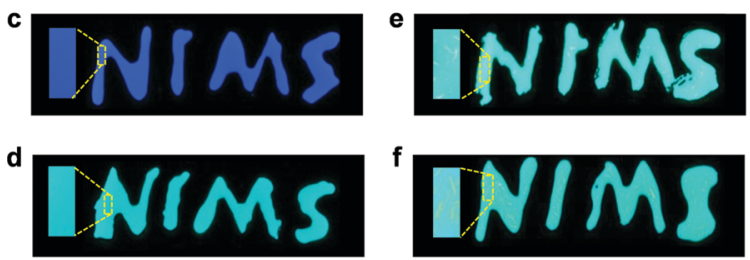

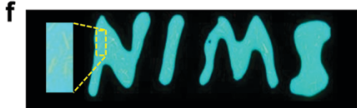

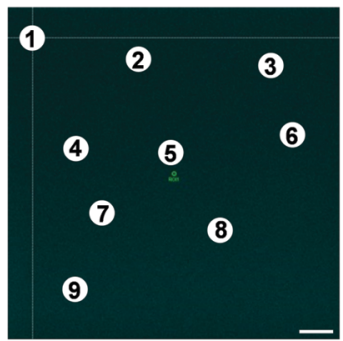

Fig. 4 Normalized fluorescence spectra of (a) 4 and (b) 1-BPEA composite IV measured at different positions of the samples as denoted in their corresponding CLSFM images in the right side. $\lambda_{\mathrm{ex}}=405 \mathrm{~nm}$. Scale bar, $20 \mu \mathrm{m}$. Photographs of the letters 'NIMS' written with (c) 1, (d) 4, and 1-BPEA composites (e) III and (f) IV under irradiation of a UV lamp (365 nm).

The emissions of liquids 1-4 exhibit a clear trend in terms of colour change from deep blue to light blue to blue-green (Fig. 3b). Therefore, the strategy for tuning the emission colour of molecular dyes, i.e., chemical modification, is applicable to luminescent molecular liquids as well. To further expand the scope of colour changes spanning from blue to red, the band gap of a well-chose liquid chromophore can be tuned more significantly by introducing suitable functional groups, a strategy that has been employed for tuning the emission colour of solid chromophores. ${ }^{4 a}$

The emission colour of $\mathbf{4}$ was shown to be similar to those of composites III and IV (Fig. 2d and 3a). However, unlike the inhomogeneous colour distributions in the 1-BPEA composites (Fig. 2c), 2-4 emitted highly uniform colours under fluorescence microscopy (Fig. 3d). When further monitored by a confocal laser scanning fluorescence microscope (CLSFM), consistent emission spectra were recorded for liquid $\mathbf{4}$ at different positions of the sample region (Fig. 4a), whereas variable emissions with different spectral shapes even at positions in close proximity were recorded for 1-BPEA composite IV (Fig. 4b). Positions 1, 2, 4, 5, and 6 in the CLSFM image (Fig. 4b) were located on part of a solid piece of BPEA and provided a luminescent feature at approximately $550 \mathrm{~nm}$, which is characteristic of BPEA solid aggregates. ${ }^{12 c}$

To verify the influence of colour homogeneity on practical applications, we demonstrated the utilization of 4 and 1-BPEA composites as fluorescent inks. As shown in Fig. 4c, the letters 'NIMS', written with liquid 1 on a glass substrate, exhibit a uniform deep-blue colour. After blending BPEA into 1, the letters turned to blue-green. However, the visual fluorescent colour is inhomogeneous. Even for composite III with $1.0 \mathrm{~mol} \%$ of BPEA, irregular bright aggregates are observed (Fig. 4e). At $5.0 \mathrm{~mol} \%$, densely distributed yellow dots and fibrils appear where the letters are written in ink (Fig. 4f). Therefore, the aggregation of BPEA in 1 strongly impairs the quality of the ink. In contrast, the colour of the letters written by liquid 4 exhibits an excellent uniformity (Fig. 4d).

\section{Conclusions}

In conclusion, our in-depth investigation on the solid-liquid composites uncovered long-existing but unnoticed and inevitable defects, i.e., phase segregation and an inhomogeneous emission colour, in a doping system. Despite the easy manipulation in blending liquids with solid dopants, such a strategy is not universal, particularly for applications in which the emission colour is critical. As an alternative, we demonstrated the applicability of chemical modification to tune the emission colour of alkyl- $\pi$ liquids, which leads to an advantageous colour quality (high uniformity and steadiness) over conventional colour tuning systems. Taking into account the facile and versatile functionality of $\pi$-conjugated molecules, this method is feasible for tailoring the functions of various optoelectronically active molecular liquids both homogeneously and systematically. We believe this strategy will remarkably enrich the family of functional molecular liquids toward their versatile applications. Another promising method for homogeneous function tuning is to increase the miscibility between molecular liquids and solid additives through proper design principles: (i) adopting an asymmetric molecular structure so that the partially exposed $\pi$-conjugated moiety can interact with other $\pi$-conjugated dopants, ${ }^{22}$ and (ii) modifying the dopant with alkyl side chains to increase the miscibility with the side chains of the liquid. ${ }^{23}$ Research in this direction and the development of highquality colour inks are progressing.

\section{Conflicts of interest}

There are no conflicts to declare.

\section{Acknowledgements}

This work was supported by Grants-in-Aid for Scientific Research (JSPS KAKENHI Grant Number JP25104011, JP15H03801, JP18H03922) from the MEXT, Japan. The authors thank Dr X. Li (NIMS) for the use of fluorescence microscope and laser scanning confocal fluorescence microscope. The authors also thank Dr K. Kawakami (NIMS) for using TGA instruments. The support of the Soft Materials Line and the MANA TSS Group at NIMS is also acknowledged. 


\section{Notes and references}

1 (a) G. Gustafsson, Y. Cao, G. M. Treacy, F. Klavetter, N. Colaneri and A. J. Heeger, Nature, 1992, 357, 477; (b) M. Gross, D. C. Müller, H.-G. Nothofer, U. Scherf, D. Neher, C. Bräuchle and K. Meerholz, Nature, 2000, 405, 661; (c) T. W. Kelley, P. F. Baude, C. Gerlach, D. E. Ender, D. Muyres, M. A. Haase, D. E. Vogel and S. D. Theiss, Chem. Mater., 2004, 16, 4413-4422; (d) K. Xiong, G. Emilsson, A. Maziz, X. Yang, L. Shao, E. W. H. Jager and A. B. Dahlin, Adv. Mater., 2016, 28, 9956-9960.

2 (a) J. Mei, N. L. C. Leung, R. T. K. Kwok, J. W. Y. Lam and B. Z. Tang, Chem. Rev., 2015, 115, 11718-11940; (b) J. N. Zhang, H. Kang, N. Li, S. M. Zhou, H. M. Sun, S. W. Yin, N. Zhao and B. Z. Tang, Chem. Sci., 2017, 8, 577-582.

3 (a) T. Kato, J. Uchida, T. Ichikawa and T. Sakamoto, Angew. Chem., Int. Ed., 2018, 57, 4355-4371; (b) S. Yagai, S. Okamura, Y. Nakano, M. Yamauchi, K. Kishikawa, T. Karatsu, A. Kitamura, A. Ueno, D. Kuzuhara, H. Yamada, T. Seki and H. Ito, Nat. Commun., 2014, 5, 4013.

4 (a) A. Wakamiya, K. Mori and S. Yamaguchi, Angew. Chem., Int. Ed., 2007, 46, 4273-4276; (b) Z. Zhang, B. Xu, J. Su, L. Shen, Y. Xie and H. Tian, Angew. Chem., Int. Ed., 2011, 50, 11654-11657; (c) I. S. Park, S. Y. Lee, C. Adachi and T. Yasuda, Adv. Funct. Mater., 2016, 26, 1813-1821; (d) E. Kim and S. B. Park, Chem. - Asian J., 2009, 4, 1646-1658.

5 (a) D. Yan and D. G. Evans, Mater. Horiz., 2013, 1, 46-57; (b) V. K. Praveen, C. Ranjith, E. Bandini, A. Ajayaghosh and N. Armaroli, Chem. Soc. Rev., 2014, 43, 4222-4242; (c) G. Liu and Y. Zhao, Adv. Sci., 2017, 4, 1700021; (d) B. Tang, C. Wang, Y. Wang and H. Zhang, Angew. Chem., Int. Ed., 2017, 56, 12543-12547.

6 (a) H. A. Behanna, K. Rajangam and S. I. Stupp, J. Am. Chem. Soc., 2007, 129, 321-327; (b) M. Mitani, M. Yoshio and T. Kato, J. Mater. Chem. C, 2017, 5, 9972-9978; (c) J. Wang, X. Yao, Y. Liu, H. Zhou, W. Chen, G. Sun, J. Su, X. Ma and H. Tian, Adv. Opt. Mater., 2018, 6, 1800074.

7 (a) G. M. Farinola and R. Ragni, Chem. Soc. Rev., 2011, 40, 3467-3482; (b) A. C. Grimsdale, K. Leok Chan, R. E. Martin, P. G. Jokisz and A. B. Holmes, Chem. Rev., 2009, 109, 897-1091; (c) H. Wu, G. Zhou, J. Zou, C.-L. Ho, W.-Y. Wong, W. Yang, J. Peng and Y. Cao, Adv. Mater., 2009, 21, 4181-4184; (d) J. Liang, L. Ying, F. Huang and Y. Cao, J. Mater. Chem. C, 2016, 4, 10993-11006.

8 (a) S. Varughese, J. Mater. Chem. C, 2014, 2, 3499-3516; (b) Q. Li and Z. Li, Adv. Sci., 2017, 4, 1600484.

9 X. Hou, C. Ke, C. J. Bruns, P. R. McGonigal, R. B. Pettman and J. F. Stoddart, Nat. Commun., 2015, 6, 6884.

10 R. Li, S. Xiao, Y. Li, Q. Lin, R. Zhang, J. Zhao, C. Yang, K. Zou, D. Li and T. Yi, Chem. Sci., 2014, 5, 3922-3928.

11 (a) Y. Sagara and T. Kato, Nat. Chem., 2009, 1, 605-610; (b) G. Graziano, Nat. Rev. Chem., 2017, 1, 0079; (c) Y. Zhao, H. Gao, Y. Fan, T. Zhou, Z. Su, Y. Liu and Y. Wang,
Adv. Mater., 2009, 21, 3165-3169; (d) L. Sheng, M. Li, S. Zhu, H. Li, G. Xi, Y.-G. Li, Y. Wang, Q. Li, S. Liang, K. Zhong and S. Zhang, Nat. Commun., 2014, 5, 3044; (e) S.-J. Yoon, J. Chung, J. Gierschner, K. Kim, M.-G. Choi, D. Kim and S. Park, J. Am. Chem. Soc., 2010, 132, 13675-13683; $(f)$ Q. Li, Photoactive Functional Soft Materials: Preparation, Properties, and Applications, Wiley-VCH, Weinheim, 2018; $(g)$ C. Xue, Y. Xue, L. Dai, A. Urbas and Q. Li, Adv. Opt. Mater., 2013, 1, 581-587.

12 (a) A. Ghosh and T. Nakanishi, Chem. Commun., 2017, 53, 10344-10357; (b) S. S. Babu, J. Aimi, H. Ozawa, N. Shirahata, A. Saeki, S. Seki, A. Ajayaghosh, H. Möhwald and T. Nakanishi, Angew. Chem., Int. Ed., 2012, 51, 3391-3395; (c) S. S. Babu, M. J. Hollamby, J. Aimi, H. Ozawa, A. Saeki, S. Seki, K. Kobayashi, K. Hagiwara, M. Yoshizawa, H. Möhwald and T. Nakanishi, Nat. Commun., 2013, 4, 1969; (d) M. J. Hollamby, A. E. Danks, Z. Schnepp, S. E. Rogers, S. R. Hart and T. Nakanishi, Chem. Commun., 2016, 52, 7344-7347; (e) F. Lu, T. Takaya, K. Iwata, I. Kawamura, A. Saeki, M. Ishii, K. Nagura and T. Nakanishi, Sci. Rep., 2017, 7, 3416; $(f)$ B. Narayan, K. Nagura, T. Takaya, K. Iwata, A. Shinohara, H. Shinmori, H. Wang, Q. Li, X. Sun, H. Li, S. Ishihara and T. Nakanishi, Phys. Chem. Chem. Phys., 2018, 20, 2970-2975.

13 (a) M. J. Hollamby and T. Nakanishi, J. Mater. Chem. C, 2013, 1, 6178-6183; (b) F. Lu and T. Nakanishi, Sci. Technol. Adv. Mater., 2015, 16, 014805.

14 G. S. Beddard and G. Porter, Nature, 1976, 260, 366.

15 S. Hirata, K. Kubota, H. H. Jung, O. Hirata, K. Goushi,

M. Yahiro and C. Adachi, Adv. Mater., 2011, 23, 889-893.

16 (a) N. Kobayashi, T. Kasahara, T. Edura, J. Oshima, R. Ishimatsu, M. Tsuwaki, T. Imato, S. Shoji and J. Mizuno, Sci. Rep., 2015, 5, 14822; (b) T. Machida, R. Taniguchi, T. Oura, K. Sada and K. Kokado, Chem. Commun., 2017, 53, 2378-2381. 17 F. Lu, K. Jang, I. Osica, K. Hagiwara, M. Yoshizawa, M. Ishii, Y. Chino, K. Ohta, K. Ludwichowska, K. J. Kurzydłowski, S. Ishihara and T. Nakanishi, Chem. Sci., 2018, 9, 6774-6778. 18 T. Förster, Discuss. Faraday Soc., 1959, 27, 7-17.

19 C. Gong, Q. Luo, Y. Li, M. Giotto, N. E. Cipollini, Z. Yang, R. A. Weiss and D. A. Scola, J. Polym. Sci., Part A: Polym. Chem., 2010, 48, 3950-3963.

20 (a) D. Xu and C. Adachi, Appl. Phys. Lett., 2009, 95, 53304; (b) T. Kasahara, S. Matsunami, T. Edura, R. Ishimatsu, J. Oshima, M. Tsuwaki, T. Imato, S. Shoji, C. Adachi and J. Mizuno, Sens. Actuators, B, 2015, 207, 481-489.

21 S. S. Zumdahl and S. A. Zumdahl, Chemistry, Houghton Mifflin Company, 7th edn, 2007.

22 M. J. Hollamby, M. Karny, P. H. H. Bomans, N. A. J. M. Sommerdjik, A. Saeki, S. Seki, H. Minamikawa, I. Grillo, B. R. Pauw, P. Brown, J. Eastoe, H. Möhwald and T. Nakanishi, Nat. Chem., 2014, 6, 690-696.

23 P. Duan, N. Yanai and N. Kimizuka, J. Am. Chem. Soc., 2013, 135, 19056-19059. 